\title{
Road Charging in the Czech Republic and EU and External Costs of Transport
}

\author{
Ladislav Bína $^{1}$, Václav Černý ${ }^{2}$ and Helena Novakova ${ }^{1}$ \\ 1. Department of Logistic and Transportation Processes, Faculty of Transportation Sciences, Czech Technical University in Prague, \\ Czech Republic
}

2. Ministry of Transport, 11015 Praha 1, Czech Republic

\begin{abstract}
In the paper the Czech toll system and its future are presented. E-toll Czech project: Facts and Figures (today) are included and the next steps in the process of developing microwave infrastructure are mentioned. In the event of possible system extension of the roads of the 1st, 2nd and 3rd class (ca 55,000 km), the satellite technology will be used. The feasibility of such a combination of these two technologies, microwave and satellite, is subject to the compatibility of both systems in terms of the control equipment. For the microwave toll system, economic analyses according to EU directives were prepared for the Czech Ministry of Transport. Special attention is paid to the problems of traffic congestion, noise and damage to the environment, on the basis of the "user pays" and "polluter pays" according to the Eurovignette Directive principles. A complete survey of the EU toll system is included in the list of information sources.
\end{abstract}

Key words: Toll system, microwave and satellite toll system, EU directive, Eurovignette Directive, economic analyses.

\section{Introduction}

In response to the situation in the surrounding states, fees started to be charged for the road network in the Czech Republic in 1995 and highway vignettes were introduced for that purpose. The motive was to secure further funds for the development of mainly the highway network and for the prospective solution concerning related applications.

Even when in 2007 an electronic toll system involving output-related payments based on the distance covered within the network of highways, speedways $(\mathrm{H}+\mathrm{S})$ and selected sections of the roads of the 1st class was introduced in the Czech Republic for vehicles in the weight category of $12 \mathrm{t}$ and more, the highway vignettes remained for the other categories of vehicles.

At that time, toll for various categories was already collected and still is collected in a number of countries.

Corresponding author: Ladislav Bína, CSc., PhD, associate professor, research fields: transportation, logistics, IT in transportation, project management. E-mail: bina@fd.cvut.cz.
And it is also collected in various ways. In some European states, we can still encounter the traditional stops at the toll gates at the entry to and exit from a highway; in other places, an electronic toll system and other telematic applications have already been implemented.

As concerns the technologies, a satellite electronic toll system (the only one in Europe) has been implemented in Germany. The microwave system (DSRC technology) has been implemented, for example, in Austria, Portugal, Norway, Spain, Italy and France. A completely different technology is operated in Switzerland - the readings from a digital recording tachometer are used, with corrections according to GPS. However, in this respect, it needs to be pointed out that the countries, which are members of the European Union, must follow the valid EU directives in the implementation of their systems, which does not apply to Switzerland, which is not a member of the Union. A number of other countries are preparing implementation of an electronic toll system (Poland, Slovakia, Netherlands, Hungary and others). A number 
of countries, or rather cities, have implemented and are implementing a metropolitan electronic toll system (London, Oslo, Stockholm) or integration of the metropolitan and highway systems (the United Kingdom). Charging toll for roads, highways and cities is not found only Europe; we can find it, for example, in Singapore, in the USA (in the state of Oregon) and in other places. The EU directive makes it possible to continue to apply special charges for some sections (in the mountains and the like). A list of the toll systems in Europe and in Switzerland is contained in the study [3].

With regard to the interoperability of the toll systems within the EU, there is a European Commission Decision of 6 October 2009 on the definition of the European Electronic Toll Service and its technical elements (EETS). According to this decision, the EETS system should be implemented in the EU within 3 years from the year 2009 .

\section{Implementation of an Electronic Toll System in the Czech Republic}

In the period of the years 2002 and 2003 and other years, various studies and experts' statements were prepared and works and opinions of experts, the Ministry of Transport of the Czech Republic and other institutions and scientific centres were presented on electronic toll.

Already at the time when the task was defined, it was emphasised that the money collected from the output-related payment system as well as the money collected from the time system (vignettes) would be used solely for reconstruction of, repairs to and construction of the road network, including its development, also connected with the issues of traffic regulation, information, telematics and safety. The preparation of the implementation of the toll system was also based on the European Directives particularly 1999/62/EC and 2006/38/EC, and the 2004/52/EC directive (interoperability) will also continue to apply to the Czech Republic.

The year 2003 was also the preparatory year for the preparation and selection of source materials for examination of the implementation of a toll system and materials such as "Plans for the output-related payments for the road infrastructure of the Czech Republic" were discussed. At the same time, a working group for designing the system of output-related payments for the road infrastructure was set up. In 2004, the preparations for the decision on introduction of toll were completed and the subsequent works performed to ensure the preparations for the construction of the system were finished (this involved making the legislative, organisational, supplier-related and other arrangements in order to make the implementation of the system possible). The Governmental Resolution No. 481 titled "Decision on the plan to implement output-related payment system for certain categories of road motor vehicles on selected roads in the Czech Republic" was also approved in that year.

The main milestones of the implementation of ETC (electronic toll collection) in the Czech Republic:

05/2004 - the government of the Czech Republic approved the plan to implement the electronic toll system

01/2005 - the government of the Czech Republic approved a proposal for implementation of the electronic toll system

06/2005 - the Minister of Transport announced a public procurement selection procedure for a contractor that would carry out the electronic toll system project

11/2005 - the Ministry of Transport announced the winner of the election procedure (the Kapsch consortium)

03/2006 - the Ministry of Transport signed a contract with the Kapsch consortium

$04 / 2006$ - the works on the implementation of electronic toll within the scope of Stage 1 were started

$12 / 2006$ - the implementation of the electronic toll project was completed within the scope of Stage 1

01/2007 - operation of Stage 1 was started

After complicated negotiations, an amendment to the existing contracts with the general contractor 
supplying the system and the services was entered into on $27 / 12 / 2007$, the main intentions of which can be summarised in the following bullet points:

- the microwave system (DSRC) will be used not only for the existing $\mathrm{H}+\mathrm{S}$ network but also for all the new parts of the $\mathrm{H}+\mathrm{S}$ network to be constructed by 2017 ;

- the payments for the roads of the 1st class will be reduced to transit links;

- payments for other roads of the 1 st class and lower classes will be the topic of discussion between the working group of the Minister of Transport and the expert team of the ministry of Transport (Faculty of Transport, Czech Technical University (FT CTU).

The act of entering into the amendment was influenced by the experienced with the operation of the Stage 1 of the toll system. Regions call for introduction of charges for roads of lower classes because of the possible by-passing of the charged sections of $\mathrm{H}+\mathrm{S}$; however, on the roads of lower classes, it is not possible to use the DSRC system - involving the construction of toll gates - without exceptional costs and restrictions (due to considerable number of exits). In this situation, the expert team of the FT CTU came with the concept of what is referred to as a hybrid solution. In this case, it is envisioned that satellite technology will be used for the roads of lower classes; but this technology must be compatible with the existing microwave system so that the existing equipment (particularly the central system) can be utilised to the maximum degree.

Organisation of the construction and operation management of ETC in the Czech Republic

Investor/Buyer: Ministry of Transport of the Czech Republic (MD ČR).

Operator: Road and Motorway Directorate of the

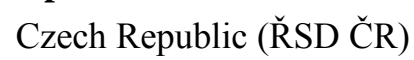

Mobile Enforcement: Customs Administration of the Czech Republic (GŘC ČR).

Project Manager: Consortium of Deloitte Czech Republic and Bovis Lend Lease, a.s.
General Contractor and operator of services of ETC: Kapsch Consortium. Kapsch has provided the complete operation services for the Czech Republic since January 2007. The total term of the contract is 10 years.

\section{Auditor: Logica}

The whole ETC project has been divided into 6 stages in the Czech Republic according to the following overview:

\section{Stage 1}

The first stage was launched on January 1, 2007: 970 $\mathrm{km}$ of highways and speedways.

\section{Stage 2}

Since January 1, 2008; $170 \mathrm{~km}$ of first class roads. (the primary Stage 2 was reduced from 1,300 km first class roads).

\section{$\underline{\text { Stage } 3}$}

Completion of the toll system for the highway and motorway network with the microwave technology (including roads to be newly built by 2017).

\section{Stage 4}

Toll system installation for vehicles with over 3.5 tons maximum gross weight (Road network amendment to the Act. $347 / 2009$ as of $01 / 01 / 2010$ )

\section{$\underline{\text { Stage } 5}$}

Telematics and Line traffic control on motorway D 1 - at present, equipment is being developed for operational traffic information.

\section{Stage 6}

System extension for the roads of the 1st, 2nd and 3rd class $(55,000 \mathrm{~km})$ by means of the satellite technology. "Hybrid system" is a combination of these two technologies (microwave and satellite navigation). There is a requirement that the two systems must be compatible as concerns their control equipment.

The following Fig. 1 shows a map of the charged road network of the Czech Republic in 2009, and the additional construction of the backbone network of $\mathrm{H}+\mathrm{S}$ with length of ca 1,800 km should be completed by 2017. The diagram of the ETC system of the Czech Republic is on Fig. 2. 
The economic results of the parts of the ETC system implemented so far in the Czech Republic are as follows [2]:

- the toll collected in 2007 amounted to 213 M EUR (with exchange rate of $1 \mathrm{EUR}=26.45$, this amounts to 5.63 billion $\mathrm{CZK}$ ).
- $\quad$ the toll collected in 2008 was 245 M EUR (6.48 billion $\mathrm{CZK}$ ).

- the estimated amount of the toll collected for the year 2009 is 207 M CZK (5.47 billion CZK).

- $\quad$ by September 2009, 420 thousand active OBUs were registered in the system.

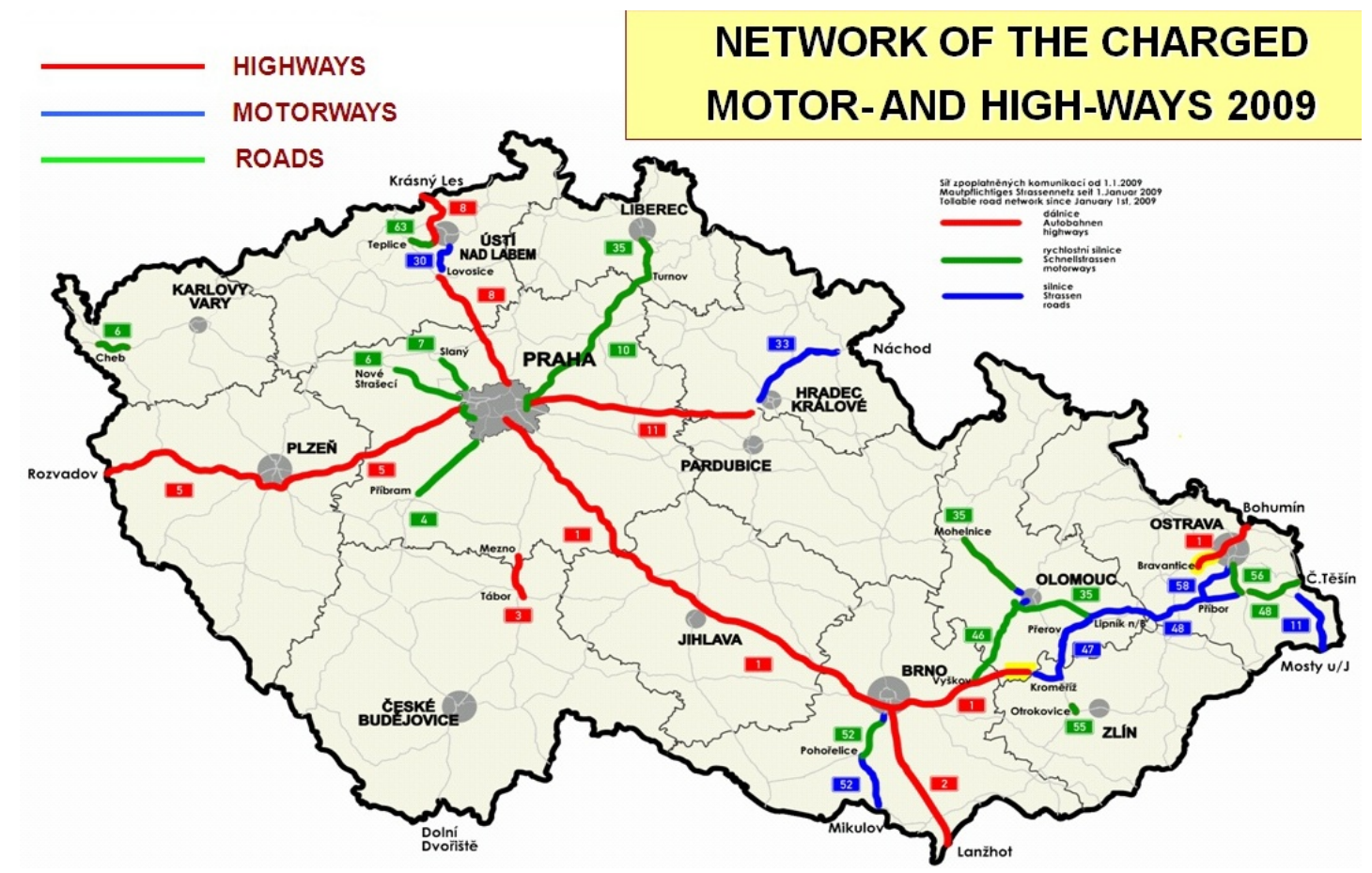

Fig. 1 Map of the charged road network in the Czech Republic in 2009 (Source: The Ministry of Transport of the Czech Republic).

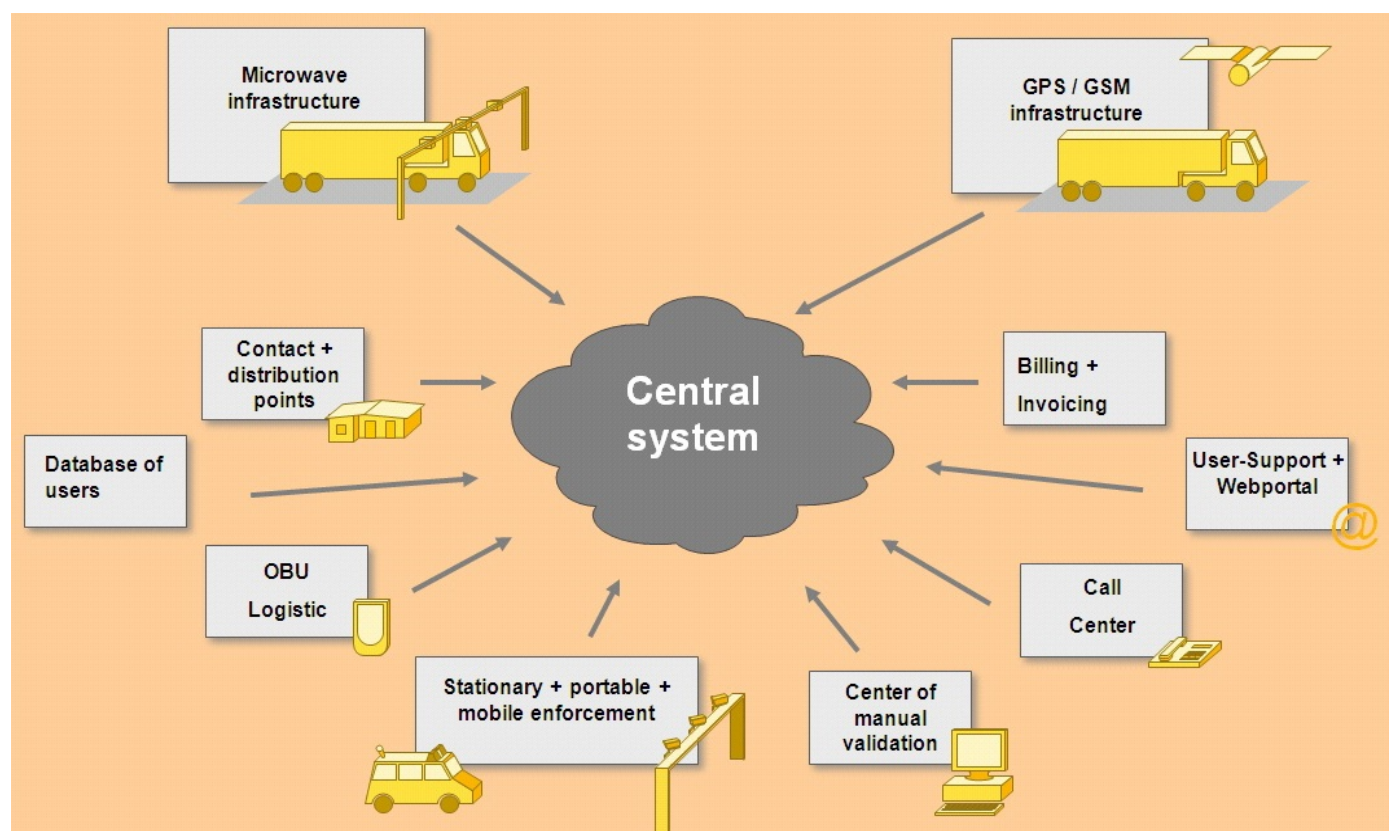

Fig. 2 Diagram of the ETC system of the Czech Republic (Source: The Ministry of Transport of the Czech Republic). 
On $01 / 01 / 2010$, a mandatory toll will also be introduced for trucks between 3.5 and 12 tons - Stage 4 of the project.

\section{Another Major Application Will Be Introduction of Differentiated Toll in the Afternoon Hours on Friday}

Internalisation of the external costs is the main priority of the transport policy of the EU. The basic principle is to charge the vehicles, which have a negative impact on the environment and health and which generate a noise burden on the surroundings of the roads and congestions. One of the works on the topic of charging transport externalities in road transport is the work of the Joint Research Centre JRC European Commission [5].

- In the Czech Republic, it was necessary to address the situation concerning the restriction of operation of vehicles in the Czech Republic. Section 43 of the Act No. 361/2000 Sb. (Sb. = Collection of Laws) on the traffic on roads and on changes to some Acts (the Road Traffic Act) defines the scope and the periods of restrictions on the travel of some vehicles. Trucks and special automobiles and special vehicles with the maximum admissible weight exceeding 7,500 kg and trucks and special automobiles and special vehicles with the maximum admissible weight exceeding 3,500 $\mathrm{kg}$ with an attached trailer vehicle are prohibited from driving on a highway and a 1st class road

(a) on Sundays and on public holidays as defined in special legislation" (hereinafter referred to as the "rest day") from 13:00 to 22:00;

(b) on Saturdays in the period from 1 July to 31 August from 7:00 to 13:00;

(c) on Fridays in the period from 1 July to 31 August from 17:00 to 21:00.

Within the governmental and parliamentary activities and a number of negotiations with road forwarders and their professional organisations, a proposal for higher charges for the Friday trips of vehicles weighing more than 3.5 tons on Friday afternoons was accepted as a measure to reduce congestions on the highway network of the Czech Republic during Friday afternoon hours on an all-year-round basis and on the following conditions:

- The existing legislation restrictions on the vacation traffic remain in effect.

- On Fridays from 15:00 to 21:00, the toll rates are increased by $25 \%$ for vehicles with 2 axles and by $50 \%$ for vehicles with 3,4 and more axles, on an all-year-round basis. The earlier starting hour for application of increased rates before the period of the legislation restriction (17:00 - 21:00) has been chosen because there is an increased traffic intensity level of passenger cars on Friday afternoons already after 15:00.

The proposed measure to increase Friday rates is planned to be launched on $01 / 02 / 2010$ and if it is actually implemented, it will probably be the first measure concerning differentiated rates in the EU with the aim of reducing congestions in the highway network.

\section{Implementation of a Hybrid Toll System in the Road Network in the Czech Republic}

The FT CTU expert group of the Minister of Transport of the Czech Republic for the issues of electronic toll suggested a hybrid electronic toll system for charging payments for 1st, 2nd and 3rd class roads. Several principles were defined for the hybrid system:

- With regard to the demands of the regions (regional governors), it is required to allow for control of traffic streams of road freight transport in selected parts of the road network by means of the GNSS technology (satellite technology);

- The supplier of the existing DSRC system will modify the interface for data processing in such a way so that it is possible to process data from virtual toll sections identified by the GNSS technology;

\footnotetext{
${ }^{1}$ Act No. 245/2000 Sb. on public holidays, other holidays, significant dates and rest days.
} 
- In the selection of the supplier of the parts of the GNSS sub-system, a fundamental demand will be placed on the supplier that both sub-systems (DSRC and GNSS) should form a single system, using a single OBU. A hybrid system designed in this way works as a "pan-territorial" system with the possibility of applying toll plans even to the roads of lower classes anywhere in the Czech Republic.

- the price of services to be provided by the resulting system must be comparable or lower than the original price of the contracted EFC.

At present, pilot operation of hybrid OBUs is running.

\section{Implementation of Line Control of D1 Highway}

The ETC system will also include the implementation of line control of D1 highway in the section from 0 to $246.8 \mathrm{~km}$, which will be in operation in 2010 according to the information by Kapsch. The system will comprise the following:

(1) A system of sensory detection of the traffic stream, which will include the intensity of the traffic stream, the distances between the travelling vehicles by the sensors, the current speed of the travelling vehicles and automatic detection of congestions;

(2) The system for computing the travel times, which will be creating, using all the detected data, a continuous load map of the road network and which will include a function for calculation of the travel times from any desired point to any desired destination;

(3) A monitoring camera system, which must ensure visual monitoring of the traffic, traffic events and the detection of the condition of the road;

(4) Variable traffic signs for line control of the transport.

According to Fig. 3, the experience from abroad shows that the implementation of a control system on

Legend:

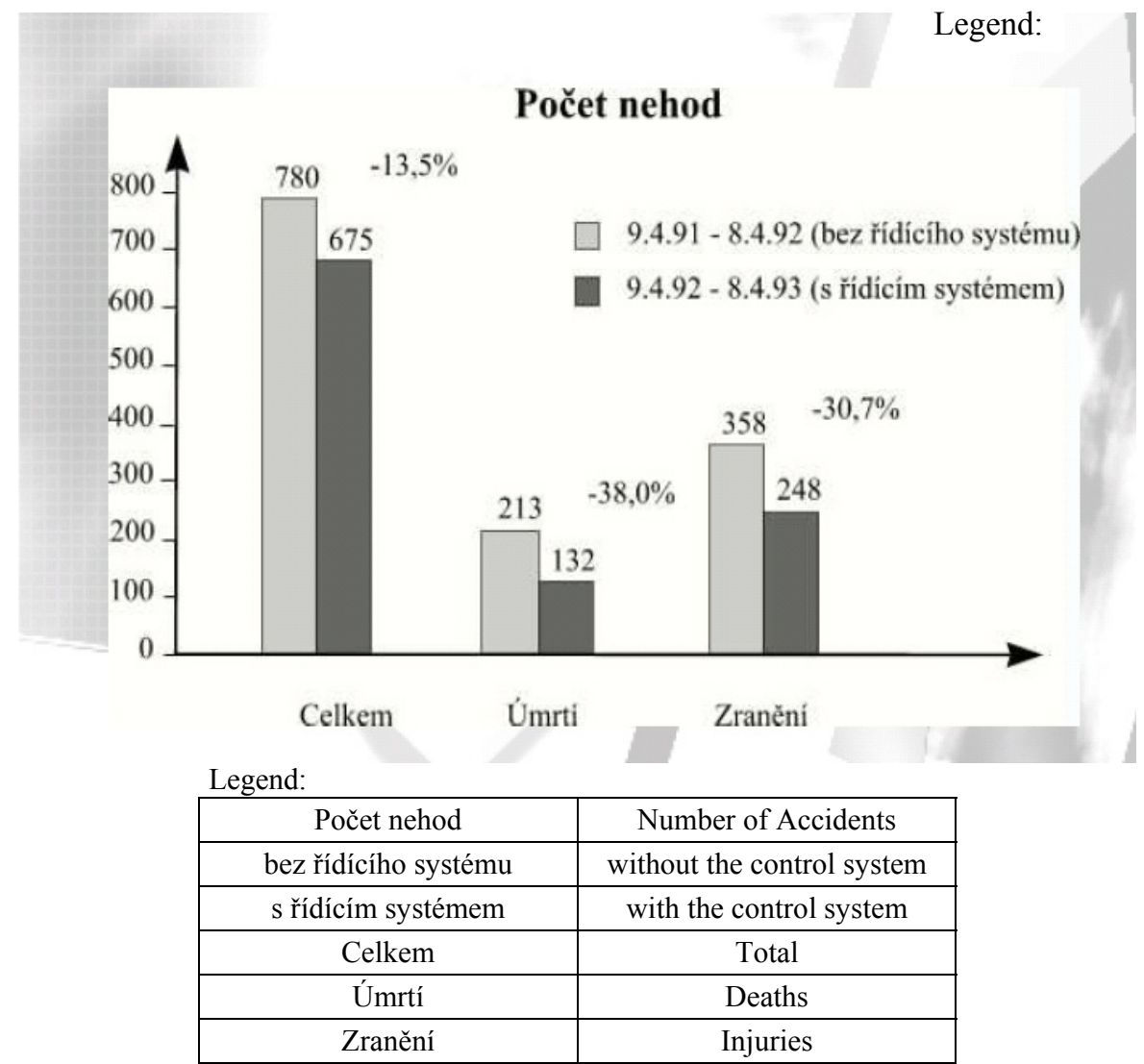

Fig. 3 The number of accidents on the A9 highway from Munich to Nuremberg (section $45 \mathrm{~km}$ with the implemented system of telematic control) [4]. 
the A9 highway from Munich to Nuremberg, significantly reduced the number of car accidents and the number of subsequent deaths and injuries.

\section{Conclusion}

The paper contains the overview of the basic specifications and activities connected with the implementation of the electronic toll system in the network of highways and other roads of the Czech Republic. The implementation of this system is an example of an indirect PPP model of financing, in which the investment and operating payments of the system are covered from the collected toll. The roll-out of the system to cover the full scope of the road network of the Czech Republic requires extensive cooperation among a number of entities participating in the implementation and operation of the system. It is also necessary to mention the cooperation of the research capacities of the Faculty of Transport of the Czech Technical University in Prague, particularly the FT CTU Expert Group of the Minister of Transport, who is the author of the design of the hybrid solution. With regard to the pressure on reduction of congestions, the proposal for differentiated toll during Friday afternoon hours when the traffic intensity level substantially rises in the highway network is also a success. The implementation of the line control of D1 highway is another product linked to the infrastructure of the electronic toll system and, according to experience from abroad, it will contribute to reducing the accident rate on this backbone highway of the Czech Republic.

\section{Reference}

[1] Černý Václav Ing., Zavedení elektronického mýta v České republice, Silniční obzor, č.5/2008.

[2] Feix Karel Ing., Czech electronic toll collection - two and half years of experiences, Praha, 15.10.2009.

[3] European Parlament, Policy Department B, Structural and Cohesion Policies, Study Pricing Policy for Road Freight Transport in EU Members States and Switzerland, 2008.

[4] Moos, P. a kolektiv: III. etapa výkonového zpoplatnění pro ČR, porada MD ČR, 7.5.2008.

[5] Council of the European Union, Land Transport, Proposal for a Directive of the European Parliament and of the Council amending Directive 1999/62/EC on the charging of heavy goods vehicles for the use of certain infrastructures, Brussels, 4 Nov., 2009.

[6] L. Bína and H. Nováková, Electronic Toll Systems and Road Transportation, in: Proceedings of Logistics \& Sustainable Transport, Celje, Slovenija, 14th-16th June, 2012, pp. 365-371.

[7] M. Svítek, Z. Bělinová and L. Bína, New study fields and trends at Faculty of Transportation Sciences, Czech Technical University in Prague, in: Proceedings Book of 5th International Scientific Symposium of Transport Faculties: Collaboration Creates Opportunities, Žilina: University of Žilina, 2011, pp. 62-73. 